Check for updates

Cite this: RSC Adv., 2017, 7, 31940

Received 26th April 2017 Accepted 13th June 2017

DOI: 10.1039/c7ra04707j

rsc.li/rsc-advances

\title{
High-performance method of carbon nanotubes modification by microwave plasma for thin composite films preparation $\uparrow$
}

\author{
Anna Dettlaff, ${ }^{a}$ Mirosław Sawczak, ${ }^{\mathrm{b}}$ Ewa Klugmann-Radziemska, ${ }^{a}$ \\ Dariusz Czylkowski, ${ }^{b}$ Robert Miotk ${ }^{b}$ and Monika Wilamowska-Zawłocka iD *a
}

\begin{abstract}
In this work we present a simple and efficient method of nitrogen plasma modification of carbon nanotubes (CNTs). The process allows for treatment of the nanotubes in the form of powder with quite a high yield (65 mg of CNTs per hour). The modified carbon nanotubes contain approx. 3.8\% nitrogen, mostly in the pyridinic form. Plasma treated CNTs exhibit better dispersibility in water and higher electric capacitance than pristine CNTs. Modified CNTs are a proper component of novel nanocomposites based on the conducting polymer poly(3,4-ethyleneidoxythiophene). Electrodeposited thin layers of the nanocomposite exhibit improved electrochemical properties (higher capacitance, better stability, lower resistance, faster diffusion) compared to the pure polymer layers.
\end{abstract}

\section{Introduction}

Carbon nanotubes (CNTs) can be described as cylindrically shaped one-dimensional nanostructures created from carbon hexagons arranged in a concentric manner. They are built from one or more graphene layers (single-walled, double-walled or multi-walled). CNTs have attracted particular research interest because of their unique features: thermal and mechanical stability, high surface area, good electrical and thermal conductivity and tunable porosity. Thus, these properties make CNTs attractive for potential application in the fields of: biosensors, fuel cells, nanoscale electronics, dye-sensitized solar cells, energy storage devices, hydrogen-storage systems, piezoelectrics etc. ${ }^{1}$ However, due to the strong intertubular van der Waals forces, high hydrophobicity and chemical inertness CNTs form large aggregates. Hence, CNTs are considered as structures exhibiting poor dispersion in most solvents. ${ }^{2-4}$

An effective method to enhance chemical reactivity and to improve dispersibility is the incorporation of heteroatoms such as nitrogen, oxygen or boron into the carbon matrix. Among them, nitrogen atoms are the most conveniently used dopants due to their atomic radius $\left(0.65 \times 10^{-10} \mathrm{~m}\right)$ similar to that of carbon $\left(0.70 \times 10^{-10} \mathrm{~m}\right) .{ }^{5}$ Hence, nitrogen atoms have a feasible probability to enter the carbon lattice. Furthermore, nitrogen

${ }^{a}$ Department of Chemical Apparatus and Theory of Machines, Faculty of Chemistry, Gdańsk University of Technology, Narutowicza 11/12, 80-233 Gdańsk, Poland. E-mail: monika.wilamowska@pg.gda.pl

${ }^{b}$ Institute of Fluid Flow Machinery, Polish Academy of Sciences, Fiszera 14, 80-231 Gdansk, Poland

$\dagger$ Electronic supplementary information (ESI) available. See DOI: $10.1039 / \mathrm{c} 7 \mathrm{ra04707j}$ possesses a lone pair of electrons, which enhances the conjugative effect of the carbon nanotube lattice. Thus, nitrogendoped carbon nanotubes (N-CNTs) exhibit extraordinary electrochemical features. Nitrogen addition may provide extra electrons in the carbon lattice, which improve the number of electronic states in the conduction and valence bands. Moreover, nitrogen can act as an n-type dopant enhancing the electron mobility and electric conductivity. Furthermore, the difference in electronegativity between $\mathrm{C}$ and $\mathrm{N}$ (2.55 and 3.04, respectively) results in increasing of the reduced work-function and tunable polarization. In this case, nitrogen groups may promote the Faradaic pseudocapacitive reactions, e.g. protonation of pyridinic nitrogen in acidic media. ${ }^{5-14}$

Incorporated nitrogen can create different configurations., ${ }^{5,15}$ Broadly speaking, there are three kinds of nitrogen incorporated in graphene sheets: pyridinic (N1), pyrrolic (N2) and graphitic-type (N3) as presented in Fig. 1. Each of them possesses distinct localized electronic features.

In particular, pyridinic $\mathrm{N}$ donates one $\pi_{z}$ electron to the ring. In pyridine the lone electron pair is in an $\mathrm{sp}^{2}$ orbital perpendicular to the $\mathrm{p}$ orbitals in the aromatic ring and does not interact with them. Pyrrolic-type $\mathrm{N}$, in turn, contributes two $\pi_{z}$ electrons originated from the lone pair, to the $\mathrm{p}$ carbon orbitals. Moreover, the nitrogen atom is $\mathrm{sp}^{3}$ hybridized. On the other hand, the quaternary $\mathrm{sp}^{2}$ hybridized nitrogen is considered as $\mathrm{N}$ which replaces the $\mathrm{C}$ atom in the lattice. Substitutional nitrogen can change the local density state around the Fermi level of local carbon atoms. ${ }^{17}$ Generally, pyrrole-like and pyridine-like nitrogen improve the capacitive behaviour and substitutional nitrogen enhances the electronic transfer. ${ }^{8}$ Thus, doping with nitrogen atoms has been considered as a feasible strategy in improving properties of CNTs. 

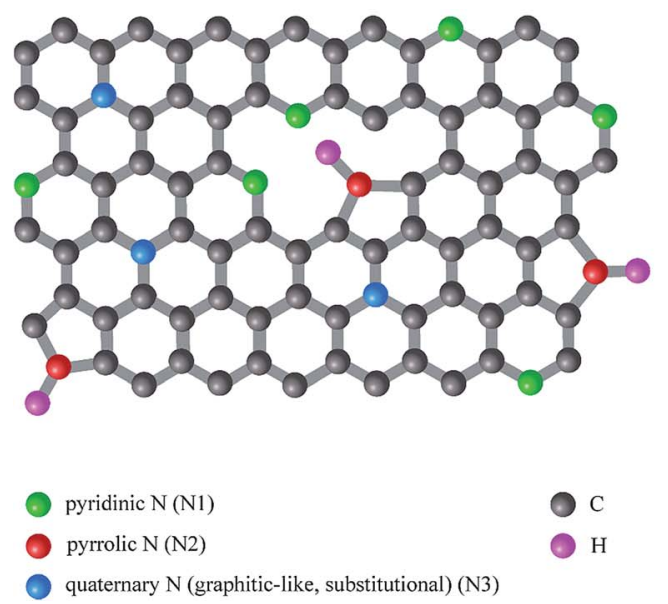
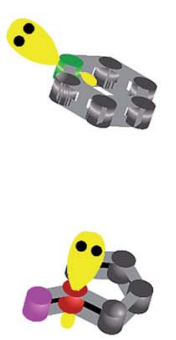

$\mathrm{C}$

$\mathrm{H}$

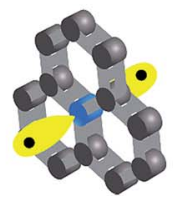

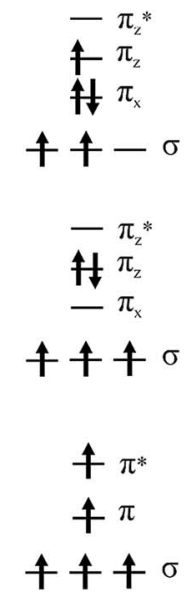

Fig. 1 Bonding and electron configurations for $\mathrm{N}$ in the carbon lattice.

N-CNTs may be obtained by two methods: (i) in situ synthesis, which is based on direct carbonization of nitrogenrich precursors, and (ii) post-treatment functionalisation, which refers to the modification of previously obtained carbon nanotubes. The most commonly used in situ techniques are: (i) spray pyrolysis - chemical vapour deposition - $\mathrm{CVD}^{18-28}$ (plasma enhanced PECVD, ${ }^{8,29-32}$ thermal CVD, ${ }^{27,29,33,34}$ aerosol-assisted CVD,${ }^{35,36}$ high-vacuum CVD - HVCVD,${ }^{37}$ etc.), and (ii) chamber pyrolysis. ${ }^{38-46}$ Less frequently used are: the arc discharge technique $^{47-49}$ and hydrothermal carbonization..$^{50}$ On the other hand, the post-treatment strategy includes chemical modification, ${ }^{51-55}$ thermal (heating in ammonia atmosphere or carbonization with N-rich precursors located on the CNTs surface ${ }^{56}$ ) and plasma treatment. ${ }^{44}$ Among these methods, the plasma approach possesses many advantages: it is solvent-free, less time-consuming and allows to control the synthesis condition. Moreover, it is rather a non-destructive method for CNTs structure, so it does not exacerbate the electrical properties of nanotubes. ${ }^{57}$

Generally, direct N-doping of carbon nanotubes in the form of powder is less studied due to the difficulty of uniform functionalization. ${ }^{58}$ There are a few reports concerning the N-doping process of powder CNTs: (i) by using plasma reactors ${ }^{59-62}$ or (ii) by plasma treatment of previously immobilized CNTs. ${ }^{63,64}$ To the best of our knowledge, this work is the first report on flowing plasma treatment of carbon nanotubes.

Herein, we report a facile method of plasma modification of carbon nanotubes. Moreover, plasma modified carbon nanotubes ((p)N-CNTs) were used as a component for preparation of nanocomposites based on conducting polymer poly(3,4ethylenedioxythiophene) (pEDOT). The electrochemically synthesized thin layers of nanocomposite ((p)N-CNTs/pEDOT/ PSS) were studied as electrodes for supercapacitor application.

\section{Experimental}

\subsection{Chemicals}

Multi-walled carbon nanotubes ( $\geq 98$ carbon basis; O.D. $\times$ I.D. $\times \mathrm{L} 10 \mathrm{~nm} \pm 1 \mathrm{~nm} \times 4.5 \mathrm{~nm} \pm 0.5 \mathrm{~nm} \times 3-6 \mu \mathrm{m}), 3,4-$ ethylenedioxythiophene (EDOT) monomer, poly(sodium 4-styrenesulfonate (PSSNa) and 4-(1,1,3,3-tetramethylbutyl)phenylpolyethylene glycol (Triton $\left.{ }^{\mathrm{TM}} \mathrm{X}-100\right)$ were supplied by SigmaAldrich (Germany). Salts and acids: $\mathrm{KCl}, \mathrm{Na}_{2} \mathrm{SO}_{4}, \mathrm{HCl}, \mathrm{H}_{2} \mathrm{SO}_{4}$ (Avantor Performance Materials Poland S.A.) were of analytical grade and used without purification. 1-Methyl-2-pyrrolidinone (NMP) (BASF, Germany) and polyvinylidene fluoride (pVDF) (Solef, Germany) were used as received. Nitrogen (Air Liquide Polska) of purity greater than or equal to 99.995 (\% vol.) was used as the plasma forming gas.

\subsection{Plasma modification of carbon nanotubes}

In classical plasma systems the microwave (MW) of radio frequency (RF) plasma is generated in a low pressure closed chamber. In such a configuration plasma affects only the surface of the material disposed in the chamber. In case of samples in the form of powder, especially conductive powders, i.e. carbon nanotubes, that tend to agglomerate, the energy of electromagnetic radiation does not penetrate the bulk of the sample and only a small part of powder is modified. Even mixing of sample during the classical plasma process does not increase the degree of material modification. In this paper we propose an innovative method of carbon nanotubes plasma processing in flow, atmospheric pressure MW plasma. The experimental setup for plasma processing of nanotubes is presented in Fig. 2.

A waveguide-supplied microwave $(2.45 \mathrm{GHz})$ plasma source (MPS) operated at atmospheric pressure was used in this study. In such a type of MPS the plasma was generated within a dielectric (quartz) tube of inner and outer diameters and length of 10,12 and $350 \mathrm{~mm}$, respectively. Nitrogen as the plasma forming gas was introduced to the quartz tube via four gas inlets assuring a swirl flow inside the tube. Multi-walled carbon nanotubes mixed with gas (nitrogen flow seeded with the carbon nanotubes) were delivered to the plasma axially (Fig. 2). The plasma conditions (absorbed microwave power, nitrogen flow rate) were chosen experimentally to assure stable plasma source operation as well as good efficiency and repeatability of modification of carbon nanotubes. For instance, 


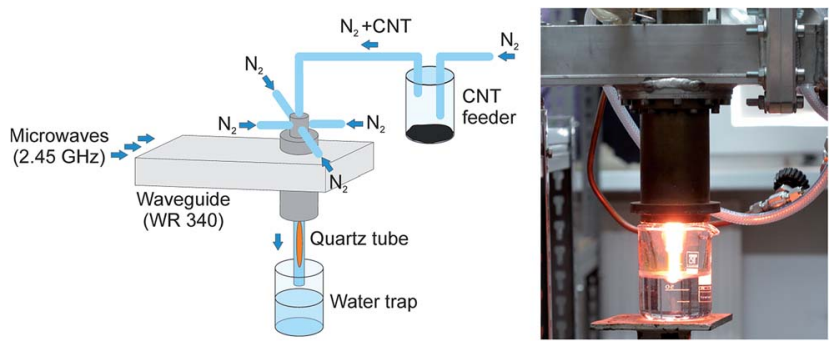

Fig. 2 Experimental setup for CNTs modification in nitrogen plasma.

increasing the absorbed microwave power resulted in MPS quartz tube overheating leading to its destruction while increasing nitrogen flow rate caused process instabilities. Hence, the total nitrogen gas flow rate of $20 \mathrm{NL} \mathrm{min}^{-1}$ and the absorbed microwave power of $1 \mathrm{~kW}$ are the experimentally optimised conditions. Additionally, thinking of scaling up the presented process and its potential industrial application it is recommended to operate with microwave of the order of $1 \mathrm{~kW}$ which allows to use cheap commercial magnetron such as that installed in microwave oven and standard waveguide components. Plasma treated nanotubes (p)N-CNTs were trapped in deionised water and afterwards, dried in vacuum (12 h). For our experiment the process efficiency was estimated to $65 \mathrm{mg}$ of nanotubes per hour. For future experiments we plan to optimize the CNTs feeder construction to improve the stability of mixing CNTs with nitrogen gas and to avoid transferring of nanotubes agglomerates to the plasma area. We expect that this will increase the efficiency of the process.

Regardless of the method described above, additional samples of carbon nanotubes were processed in a classical lowpressure RF plasma system (Femto Plasma System, Diener Electronics, Germany) operating at $13.56 \mathrm{MHz}$ and $50 \mathrm{~W}$ plasma power. Carbon nanotubes in the form of powder were processed for period of time in the range from $2 \mathrm{~min}$ to 1 hour in a nitrogen atmosphere (samples marked as N-CNTs). Detailed conditions of plasma treatment of investigated CNTs samples by both methods and corresponding pictures of their aqueous suspensions are gathered in Table S1 and Fig. S1, respectively (see $\mathrm{ESI}_{\dagger} \dagger$ ).

The aim of functionalization of carbon nanotubes is to increase their hydrophilicity and hence improve their dispersibility in polar solvents. Pristine carbon nanotubes (CNTs) and plasma treated carbon nanotubes were dispersed ultrasonically in water. Pristine CNTs, as well as N-CNTs remain agglomerated even after surfactant addition, whereas (p)NCNTs disperse homogenously in pure water (Fig. S1 in ESI†).

\subsection{Preparation of electrode layers}

Pristine and N-doped carbon nanotubes electrode layers were prepared by the dip-coating technique. Firstly, $25 \mathrm{mg}$ of CNTs and (p)N-CNTs powders were dispersed in $4 \mathrm{~mL}$ of 1-methyl-2pyrrolidinone by sonication $(20 \mathrm{~h})$. Secondly, poly(vinylidene fluoride) binder was added. The weight ratio between CNTs and pVDF was 9 to 1 . Afterwards, the slurries were mixed by sonication and then concentrated until the required viscosity was obtained by slow evaporation of solvent by heating $\left(80^{\circ} \mathrm{C}\right)$ and stirring. Then, deposition of the slurries on Pt wires by the dip-coating technique was carried out. The last step was drying of the layers in a vacuum dryer. For electrochemical measurements only coatings of similar weight were used.

Nanocomposite layers based on nitrogen-doped carbon nanotubes and poly(3,4-ethylenedioxythiophene) with poly(4styrenesulfonate) counter-ions ((p)N-CNTs/pEDOT/PSS) were prepared by electrochemical deposition at $+0.87 \mathrm{~V}$ from an aqueous solution containing $1 \mathrm{mg} \mathrm{mL}^{-1}$ of $\mathrm{N}$-doped carbon nanotubes, $15 \mathrm{mM}$ EDOT and 0.1 M PSSNa. The electrochemical synthesis was performed in a three-electrode cell configuration. The working electrodes were: glassy carbon disc electrodes $\left(0.0314 \mathrm{~cm}^{2}\right)$, platinum disc electrodes $\left(0.0177 \mathrm{~cm}^{2}\right)$ or platinum plates $\left(0.5 \mathrm{~cm}^{2}\right)$, the reference electrode was $\mathrm{Ag}|\mathrm{AgCl}| 0.1 \mathrm{M} \mathrm{KCl}$ and platinum mesh served as the counter-electrode. The deposition charge was equal to $0.2 \mathrm{C} \mathrm{cm}^{-2}$. The concentration of (p)N-CNTs in the synthesis solution was selected according to our previous research. ${ }^{65}$

\subsection{Characterization techniques}

X-ray photoelectron spectroscopy (XPS) spectra of pristine and functionalised carbon nanotubes were measured using an Escalab 250Xi spectroscope (ThermoFischer Scientific, United Kingdom) with a monochromatic Al K $\alpha$ source. Samples were studied in the form of powder. Spectra were acquired at constant analyser pass energy of $10 \mathrm{eV}$ with $0.1 \mathrm{eV}$ steps and were fitted with mixed Gaussian-Lorenzian peaks after Shirleytype background subtraction.

The structure of the (p)N-CNTs/pEDOT/PSS and CNTs/ PEDOT/PSS electrode layers were characterized by a scanning electron microscope (SEM) FEI Quanta FEG 250. The $10 \mathrm{kV}$ beam accelerating voltage was used with a Secondary ElectronEverhart-Thornley Detector (SE-ETD) working in high vacuum mode pressure $10^{-4} \mathrm{~Pa}$.

Raman spectra of CNTs and (p)N-CNTs powders were obtained with a confocal InVia, Renishaw micro-Raman spectrometer. The excitation wavelength was $514 \mathrm{~nm}$ (Ar ion laser), and the wavenumber was in the range of $100-3200 \mathrm{~cm}^{-1}$.

The electrochemical properties of carbon nanotubes and composite layers were investigated by cyclic voltammetry $(\mathrm{CV})$, chronopotentiometry (ChP) and electrochemical impedance spectroscopy (EIS) using the AUTOLAB $302 \mathrm{~N}$ potentiostat-galvanostat (AUTOLAB, Eco Chemie, B.V., Netherlands) under Nova software. All electrochemical tests were carried out in a three-electrode electrochemical cell under argon atmosphere. The $\mathrm{Ag}|\mathrm{AgCl}| 0.1 \mathrm{M} \mathrm{KCl}$ electrode and Pt mesh served as the reference and the counter electrode, respectively.

\section{Results and discussion}

\subsection{Characterization of pristine and nitrogen-doped carbon nanotubes}

Pristine and plasma treated carbon nanotubes were investigated by X-ray Photoelectron Spectroscopy and Micro-Raman 
Table 1 Curve fitting results of $\mathrm{C} 1 \mathrm{~s}, \mathrm{O}$ 1s and $\mathrm{N}$ 1s spectra of pristine carbon nanotubes and nitrogen-doped carbon nanotubes

\begin{tabular}{|c|c|c|c|c|c|c|c|c|c|}
\hline & \multicolumn{2}{|c|}{ Pristine CNTs } & \multicolumn{2}{|c|}{$\begin{array}{l}\text { (p)N-CNTs } \\
\text { (flow plasma } 1000 \mathrm{~W} \text { ) }\end{array}$} & \multicolumn{2}{|c|}{$\begin{array}{l}\text { (p)N-CNTs } \\
\text { (flow plasma } 250 \mathrm{~W} \text { ) } \\
\end{array}$} & \multicolumn{2}{|c|}{$\begin{array}{l}\text { N-CNTs (chamber } \\
\text { plasma } 13.56 \mathrm{MHz} \text {, } \\
50 \mathrm{~W}, 1 \mathrm{~h} \text { ) }\end{array}$} & Assignment \\
\hline \multirow[t]{3}{*}{ C 1 s } & - & - & - & - & - & - & 283.4 & 6.5 & $\mathrm{C}=\mathrm{C}$ \\
\hline & 284.6 & 78.5 & 284.6 & 54.7 & 284.5 & 90.7 & 284.6 & 45.7 & $\mathrm{C}-\mathrm{C} \mathrm{sp}{ }^{2}, \mathrm{C}-\mathrm{H}$ \\
\hline & 286.6 & 5.3 & 286.8 & 15.7 & - & - & 288.5 & 6.7 & $\begin{array}{l}\mathrm{C}=\mathrm{O}, \mathrm{C}-\mathrm{O}, \\
\mathrm{C}=\mathrm{N}, \mathrm{C}-\mathrm{N}\end{array}$ \\
\hline \multirow[t]{2}{*}{ O $1 \mathrm{~s}$} & 531.8 & 1.4 & - & - & 530.9 & 0.9 & - & - & $\mathrm{O}=\mathrm{C}$ \\
\hline & 534.2 & 0.8 & 532.7 & 6.8 & 533.2 & 1.0 & 532.4 & 6.9 & $\mathrm{O}-\mathrm{C}$ \\
\hline \multirow[t]{2}{*}{ N 1s } & - & - & 398.9 & 2.5 & - & - & 399.8 & 3.9 & Pyridinic N \\
\hline & - & - & 401.4 & 1.3 & - & - & - & - & $\begin{array}{l}\text { Pyrrolic N, } \\
\text { quaternary N }\end{array}$ \\
\hline
\end{tabular}

Spectroscopy in order to evaluate their chemical and structural changes after the nitrogen doping process.

XPS measurements were carried out mainly for verification of surface functional groups of the carbon nanotubes. The results of fitting of $\mathrm{C} 1 \mathrm{~s}, \mathrm{O} 1 \mathrm{~s}, \mathrm{~N} 1 \mathrm{~s}$ spectra are collected in Table 1.

C 1s spectra of investigated samples were resolved into signals located in the range from $283.4 \mathrm{eV}$ to $288.5 \mathrm{eV}$. The peaks are assigned to the particular carbon-carbon, carbonoxygen and carbon-nitrogen bonds according to the literature reports. ${ }^{66-69}$ Two samples after plasma treatment, namely (p)NCNTs $(1000 \mathrm{~W})$ and N-CNTs, exhibit higher amount of C-C $\mathrm{sp}^{3}$ bonds and higher amount of $\mathrm{C}-\mathrm{O} / \mathrm{C}=\mathrm{O}$ and $\mathrm{C}-\mathrm{N} / \mathrm{C}=\mathrm{N}$ bonds compared to pristine CNTs. This result suggest incorporation of oxygen and nitrogen functional groups on the CNTs surface. Moreover, XPS analysis confirmed presence of nitrogen in these two samples. The $\mathrm{N} 1 \mathrm{~s}$ spectrum is deconvoluted into two main component peaks at binding energies of $398.9 \mathrm{eV}$ and $401.4 \mathrm{eV}$. The first one can be ascribed to the pyridinic nitrogen, while the second one refers to both pyrrolic and quaternary nitrogen. ${ }^{66,70}$ The peak recorded at $401.4 \mathrm{eV}$ is not divided into two separate signals due to its weak energy. The total nitrogen content in the (p)N-CNTs $(1000 \mathrm{~W})$ and N-CNTs samples is at the same level, namely 3.8 at $\%$ and 3.9 at\%, respectively. Although both samples exhibit similar amount of nitrogen, the sample $\mathrm{N}$ CNTs modified in standard plasma system does not give homogenous suspension in water (see Fig. S1, sample E, in ESI $\dagger$ ). This leads to the conclusion that investigated classical low-pressure RF plasma (13.56 MHz, $50 \mathrm{~W}$ ) apparently does not penetrate the bulk of the sample but causes modification only at the surface of CNTs agglomerates. On the other hand, neither nitrogen atoms nor increased amount of oxygen were detected for the sample treated with lower power flow plasma (p)N-CNTs $(250 \mathrm{~W})$. Despite this fact, the sample (p)N-CNTs $(250 \mathrm{~W})$ exhibit relatively good dispersion in $0.1 \mathrm{M}$ PSSNa aqueous solution (Fig. S1, sample I, in ESI $\dagger$ ). This suggest that modification of CNTs with lower power flow plasma was insufficient. Presented results demonstrate that homogenous dispersion of CNTs in water is possible only when CNTs are modified uniformly in the bulk of the sample and when the amount of heteroatoms/ functional groups is on the proper level. The sample (p)NCNTs modified in optimised conditions (flow plasma, $1000 \mathrm{~W}$ ) was selected for further investigation.

To investigate the structure of pristine and nitrogen-doped (p)N-CNTs, a Raman spectroscopy measurement was conducted, and the results are shown in Fig. 3. In our work we utilize a five-peak model to fit first-order bands, and two peaks for the second-order ones (Fig. 4).

The spectra were deconvoluted independently after background subtraction. The results of the fitting procedure are gathered in Table 2. The first-order bands include: (i) D-band (1348 $\pm 2 \mathrm{~cm}^{-1}$ ), (ii) G-band $\left(1580 \pm 5 \mathrm{~cm}^{-1}\right)$, (iii) $\mathrm{D}^{\prime}$-band $\left(1614 \pm 4 \mathrm{~cm}^{-1}\right)$, (iv) $\mathrm{D}^{\prime \prime}$-band $\left(1496 \pm 5 \mathrm{~cm}^{-1}\right)$, and (v) I-band $\left(1216 \pm 3 \mathrm{~cm}^{-1}\right.$ ), whereas the second-order spectra can be fitted with two peaks: $2 \mathrm{D}$-band $\left(2693 \pm 3 \mathrm{~cm}^{-1}\right)$ and D + G-band $\left(2929 \pm 3 \mathrm{~cm}^{-1}\right)$. The $\mathrm{D}, \mathrm{D}^{\prime}, \mathrm{I}, \mathrm{D}^{\prime \prime}, \mathrm{D}+\mathrm{G}$ bands are assigned to the disordered symmetry of the carbon $\mathrm{sp}^{2}$ network. The disorganisation in the graphitic lattice may be caused by several effects: functional groups, in-plane defects of the tube, amorphous carbon (presence of the $\mathrm{D}^{\prime \prime}$ peak), heptagon-pentagon pair, incorporated heteroatoms, etc. $^{71-73}$ As shown in Table 2, the

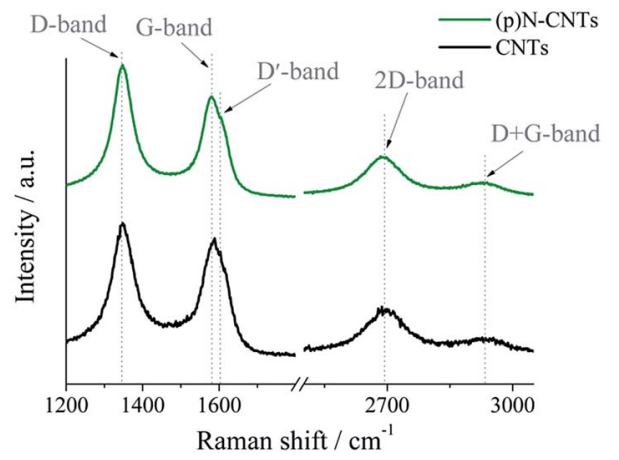

Fig. 3 Raman spectra showing differences in structure of carbon nanotubes upon the nitrogen-doping process. 

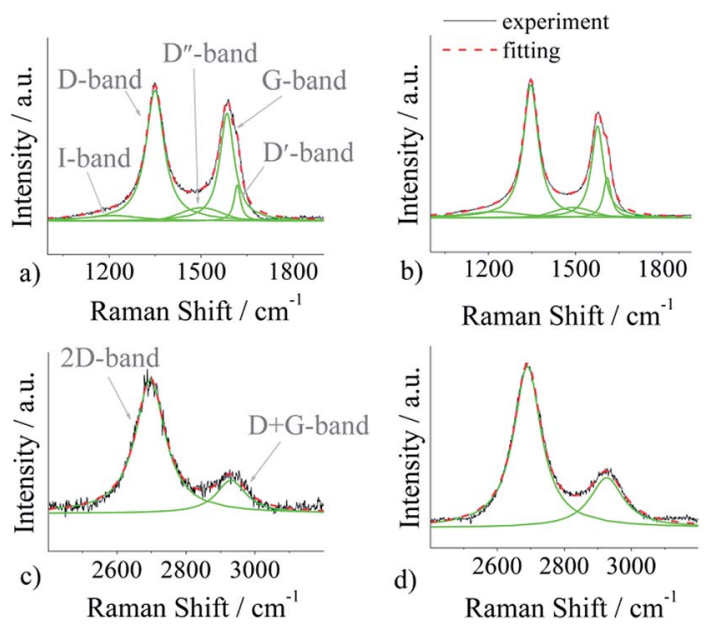

Fig. 4 Fitting of first-order Raman spectra: (a) CNTs, (b) (p)N-CNTs; fitting of second-order spectra: (c) CNTs, (d) (p)N-CNTs.

area of peaks connected with disorder in the carbon lattice has increased after plasma modification.

The results show that plasma treatment changes the structure of carbon nanotubes suggesting successful incorporation of nitrogen atoms in the carbon lattice. Moreover, the area of G and 2D bands, both associated with ordered crystalline graphitic structures, decreased after nitrogen incorporation. The Raman spectra indicate that after the process of nitrogen doping the symmetry of the carbon $\mathrm{sp}^{2}$ network definitely has exacerbated.

According to literature reports, the peak area ratio of $\mathrm{D}$ and $\mathrm{G}$ bands $\left(A_{\mathrm{D}} / A_{\mathrm{G}}\right)$ or of $\mathrm{D}^{\prime}$ and $\mathrm{G}$ peaks $\left(A_{\mathrm{D}^{\prime}} / A_{\mathrm{G}}\right)$ may be used to quantify the amount of defects in the carbon lattice..$^{29}$ As shown in Table 2, the process of nitrogen doping causes an increase of the $A_{\mathrm{D}} / A_{\mathrm{G}}$ ratio: from 1.51 for pristine CNTs to 1.80 for nitrogen doped (p)N-CNTs. The same dependence is analysed for the $A_{\mathrm{D}^{\prime}}$ $A_{\mathrm{G}}$ ratio: 0.15 for CNTs and 0.28 for (p)N-CNTs. These results indicate that the degree of disorder in graphitic lattice and edge plane exposure increases. The growth of these peak area ratios is connected with heterogeneous $\mathrm{N}$-doping onto the carbon lattice of carbon nanotubes. ${ }^{22,74}$ Thus, the resolution of Raman spectra agrees well with the XPS data.

Cyclic voltammetry curves of CNTs and (p)N-CNTs electrode layers were recorded to evaluate their electrochemical behaviour. A rectangular shape of $\mathrm{CV}$ curves (Fig. 5) confirms the capacitive character of both types of carbon nanotubes. However, nitrogen-doped carbon nanotubes exhibit higher capacitance values, probably due to the presence of surface functional groups, which may be a source of pseudocapacitance. ${ }^{11-14}$ Another reason of higher current density observed on the CV curve of (p)N-CNTs may be the more homogenous electrode layer compared to the pristine CNTs, which tends to agglomerate.

\subsection{Characterization of nanocomposite (p)N-CNTs/pEDOT/ PSS}

Plasma treated (flow plasma, $1000 \mathrm{~W}$ ) carbon nanotubes (p)NCNTs, due to their improved electrochemical properties, were

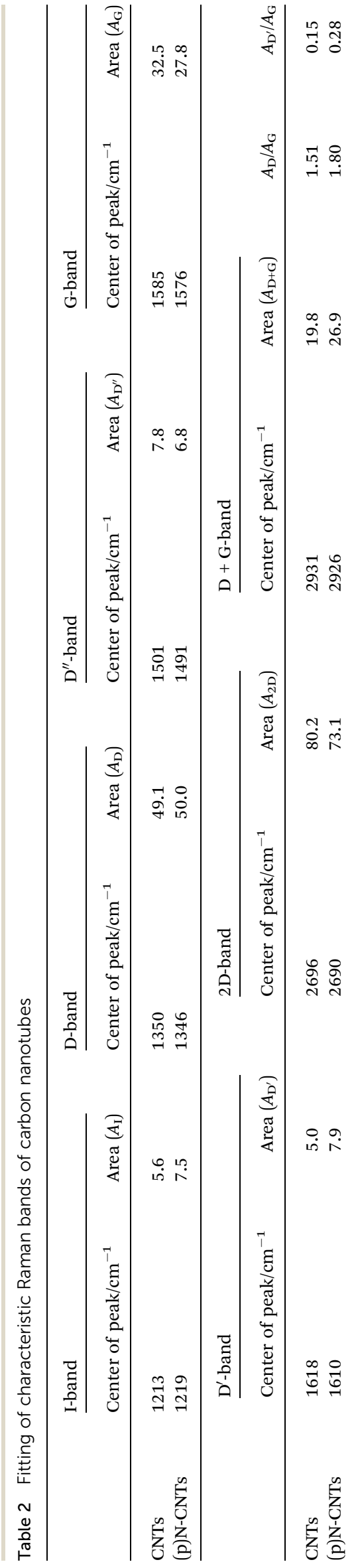




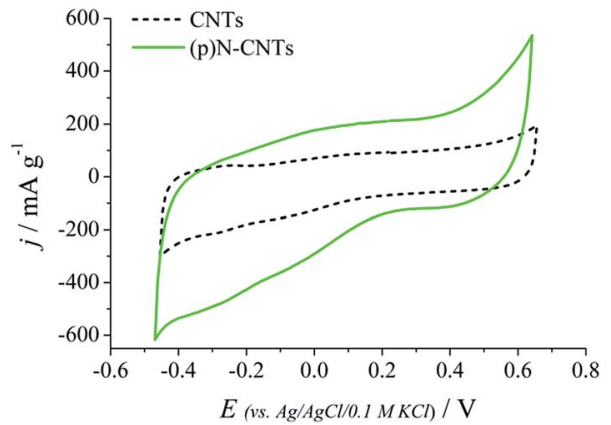

Fig. 5 CV curves of (p)N-CNTs and CNTs dip-coated on Pt wires; outer electrolyte $0.1 \mathrm{M} \mathrm{KCl}$, scan rate: $0.2 \mathrm{~V} \mathrm{~s}^{-1}$.

selected for preparation of nanocomposites based on conducting polymer $\mathrm{PEDOT}$ with polystyrenesulfonate counterions. The nanocomposite (p)N-CNTs/pEDOT/PSS layers, obtained by electrodeposition, exhibit good adhesion to the electrode substrates, eliminating the need of using any additional binder.

Scanning electron microscope measurements were taken to study the morphology and homogeneity of (p)N-CNTs/pEDOT/ PSS layers and composite with pristine carbon nanotubes CNTs/pEDOT/PSS for comparison (the CNTs/pEDOT/PSS composite was electrodeposited with the same procedure as (p)N-CNTs/pEDOT/PSS layers). As shown in SEM images (Fig. 6), both composite layers exhibit a cauliflower-like structure, which is typical for poly(3,4-ethylenedioxythiophene). ${ }^{65,75-77}$ In the case of (p)N-CNTs/pEDOT/PSS composite the presence of (p)N-CNTs is clearly visible in the SEM images. Plasma treated carbon nanotubes create entangled networks that increase porosity of the nanocomposite. As can be seen in Fig. 6a), (p)N-CNTs are

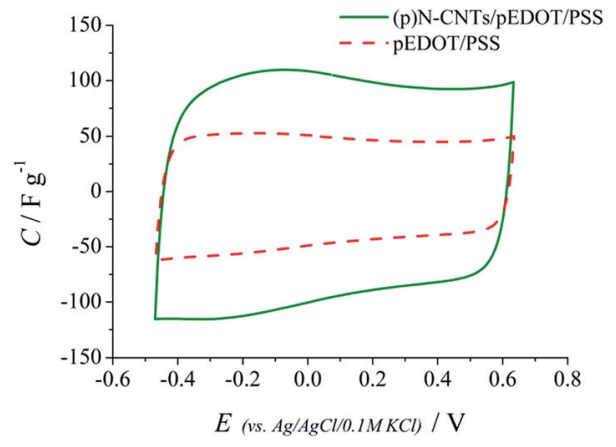

Fig. $7 \mathrm{CV}$ curves of the (p)N-CNTs/pEDOT/PSS and pEDOT/PSS electrode layers at $0.2 \mathrm{~V} \mathrm{~s}^{-1}$; outer electrolyte $0.1 \mathrm{M} \mathrm{KCl}$.

homogenously distributed within the composite. Higher magnification image of (p)N-CNTs/pEDOT/PSS (Fig. 6b) shows that polymer acts like a binder surrounding and connecting carbon nanotubes. On the other hand, SEM pictures of the CNTs/pEDOT/PSS composite do not show any evidence of presence of CNTs in the polymer matrix. The surface of CNTs/ pEDOT/PSS is quite smooth and significantly less porous than (p)N-CNTs/pEDOT/PSS. Moreover, there are places in the CNTs/ pEDOT/PSS layer with a large roughness (Fig. 6c), that may suggest random incorporation of CNTs agglomerates in the polymer.

Electrochemical measurements of the nanocomposite layers were performed in order to evaluate their usefulness as electrodes for supercapacitor application. The CNTs/pEDOT/PSS composite layers did not give reproducible results, thus the electrochemical studies for pure polymer without carbon nanotubes (pEDOT/PSS) are presented for comparison with the

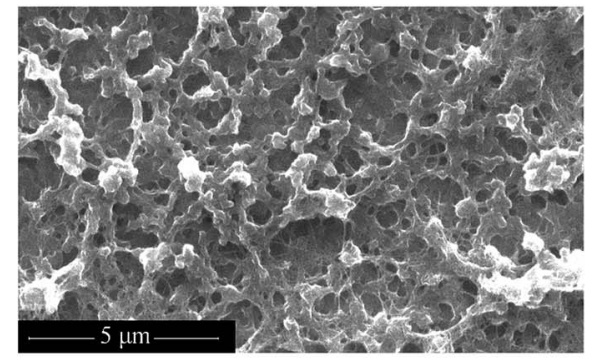

a)

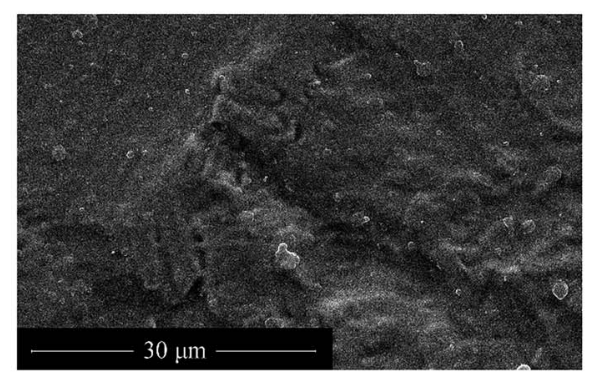

c)

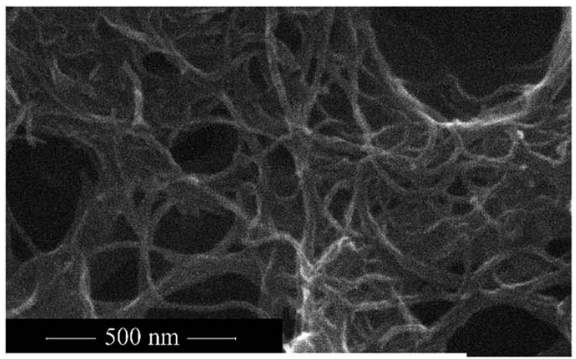

b)

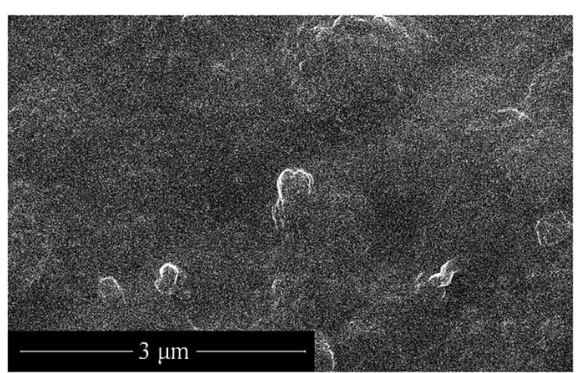

d)

Fig. 6 SEM images of the surface of electrode layers deposited on Pt substrate: (a) (p)N-CNTs/pEDOT/PSS 10 000 $\times$ magnification, (b) (p)NCNTs/pEDOT/PSS $100000 \times$ magnification, (c) CNTs/pEDOT/PSS 2500× magnification, (d) CNTs/pEDOT/PSS 25 000 $\times$ magnification. 


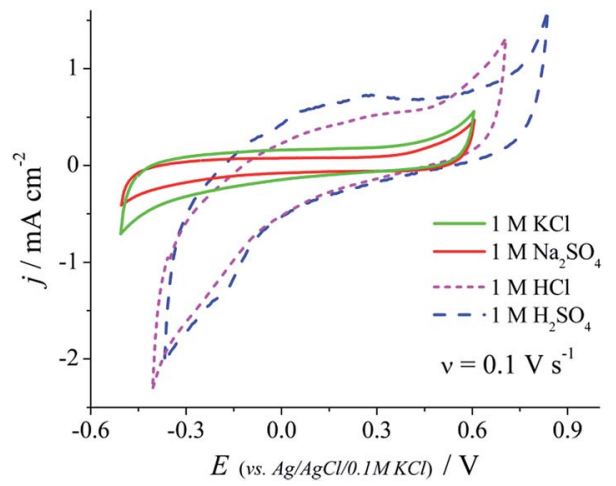

Fig. $8 \mathrm{CV}$ of the (p)N-CNTs/pEDOT/PSS electrode recorded in various electrolytes; scan rate $0.1 \mathrm{~V} \mathrm{~s}^{-1}$

(p)N-CNTs/pEDOT/PSS composite. CV curves of the nanocomposite (p)N-CNTs/pEDOT/PSS and the conducting polymer pEDOT/PSS (Fig. 7) have a rectangular shape due to the capacitive behaviour of both materials. It is worth noticing that the nanocomposite layers exhibit significantly higher capacitance values compared to the pure polymer electrodes.

The nanocomposite (p)N-CNTs/pEDOT/PSS layers were tested by cyclic voltammetry in different aqueous electrolytes: $1 \mathrm{M} \mathrm{KCl}, 1 \mathrm{M} \mathrm{Na}_{2} \mathrm{SO}_{4}, 1 \mathrm{M} \mathrm{HCl}$ and $1 \mathrm{M} \mathrm{H}_{2} \mathrm{SO}_{4}$ (Fig. 8). The capacitance values achieved by (p)N-CNTs/pEDOT/PSS electrodes are higher in acidic solution compared to the neutral ones. It may be caused by functional groups present on the (p)NCNTs surface that are more reactive in acidic solution. XPS analysis of (p)N-CNTs revealed that most of nitrogen atoms, incorporated during plasma treatment, are pyridine-like, which may be protonated in acidic media. ${ }^{11,14}$ Moreover, oxygen functional groups (i.e. quinone/hydroquinone), which are also present on the (p)N-CNTs surface, may be a source of additional pseudocapacitance in acidic electrolytes. ${ }^{12,14,65,78,79}$

Prolonged galvanostatic charge-discharge measurements of the (p)N-CNTs/pEDOT/PSS nanocomposite and pEDOT/PSS conducting polymer electrodes were performed to evaluate the

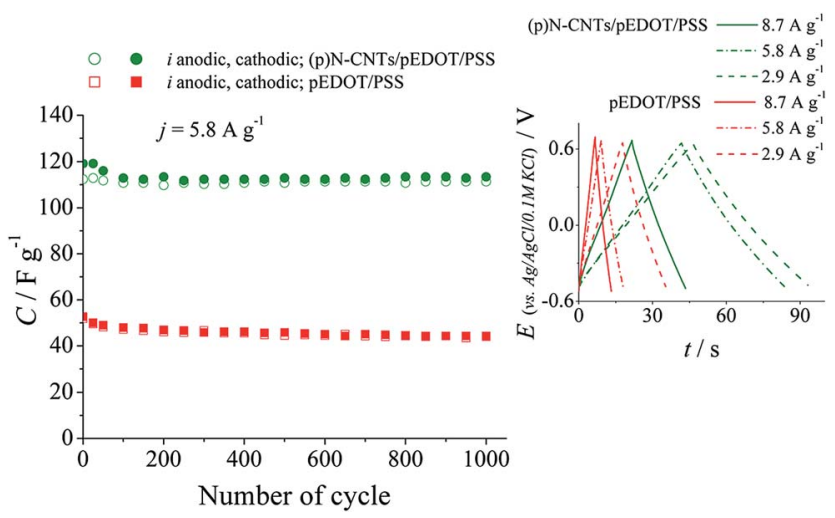

Fig. 9 Chronopotentiometry tests of the (p)N-CNTs/pEDOT/PSS and pEDOT/PSS electrode layers recorded at $5.8 \mathrm{~A} \mathrm{~g}^{-1}$ in $0.1 \mathrm{M} \mathrm{KCl} \mathrm{elec-}$ trolyte; inset: examples of chronopotentiometry curves recorded at different current densities in $0.1 \mathrm{M} \mathrm{KCl}$ electrolyte.

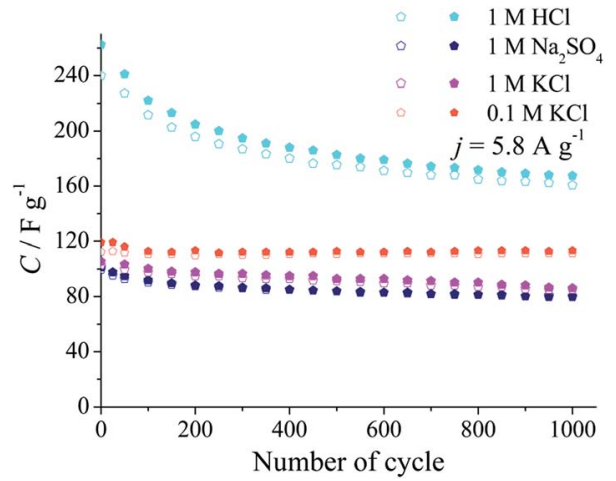

Fig. 10 Chronopotentiometry tests of the (p)N-CNTs/pEDOT/PSS electrode layer recorded in various electrolytes at $5.8 \mathrm{~A} \mathrm{~g}^{-1}$ current density; empty symbol - anodic current, full symbol - cathodic current.

cyclability and the specific capacitance values. The results are presented in Fig. 9. The composite electrodes exhibit nearly two times higher capacitance values over thousands of chargedischarge cycles compared to the polymer electrodes. Moreover, the capacitance retention after 1000 cycles is higher for the composite (95\%) than for the polymer (85\%). Better stability of the (p)N-CNTs/pEDOT/PSS nanocomposite electrode layer is probably due to improved mechanical properties caused by the presence of plasma treated carbon nanotubes. ${ }^{80}$ Chronopotentiometric curves recorded at different currents (inset in Fig. 9) are symmetrical, confirming fast and reversible charge-discharge processes of investigated nanocomposite electrode layers.

Multicyclic chronopotentiometry tests were performed in different electrolytes (Fig. 10). The capacitance retention after thousands of cycles in neutral electrolytes is much higher (78$95 \%$ ) compared to the acidic solution (67\%). On the other hand, the capacitance values are two times higher in acidic media, which is in agreement with the results obtained from cyclic voltammetry measurements.

Electrochemical impedance spectroscopy measurements were carried out to examine the electrochemical behaviour, in particular the electrode kinetics, the capacitance and chargetransfer resistance of the investigated layers and the solution resistance. EIS analyses were conducted in contact with $1 \mathrm{M} \mathrm{KCl}$ electrolyte, in the frequency range from $25 \mathrm{kHz}$ to $0.1 \mathrm{~Hz}$ with

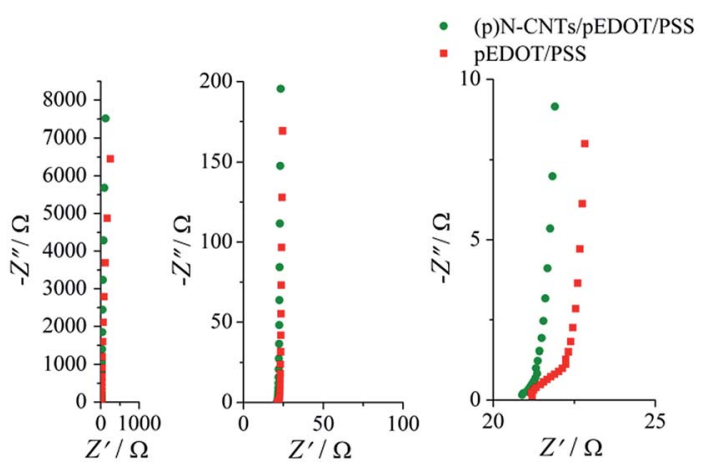

Fig. 11 Nyquist impedance plots of the (p)N-CNTs/pEDOT/PSS and pEDOT/PSS; outer electrolyte $1 \mathrm{M} \mathrm{KCl}$. 


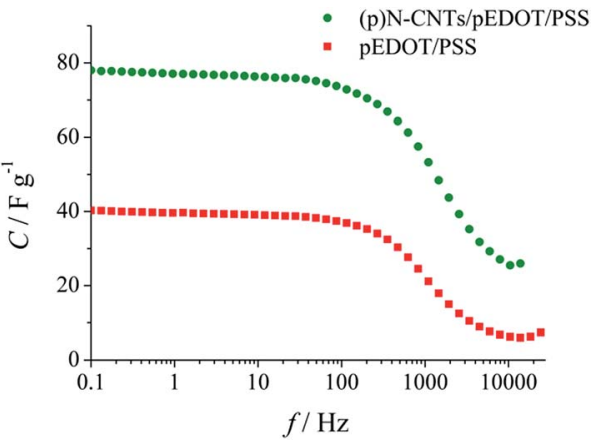

Fig. 12 Bode plots of (p)N-CNTs/pEDOT/PSS and pEDOT/PSS; outer electrolyte $1 \mathrm{M} \mathrm{KCl}$.

the amplitude equal to $10 \mathrm{mV}$. EIS spectra were recorded at a rest potential equal to $0.10 \mathrm{~V}$ and $0.25 \mathrm{~V}$ for the pEDOT/PSS and (p)N-CNTs/pEDOT/PSS layers, respectively. The Nyquist plots are presented in Fig. 11. The intercept of the curve with the real impedance axis gives an estimate of the solution resistance, which is equal to approximately $21 \Omega$. In the high- and midfrequency region a line at a slope of about 45 degrees is present on both Nyquist plots. This domain is due to the distributed resistance/capacitance in the porous electrode and can be described by the finite transmission line model. ${ }^{\mathbf{8 1 - 8 3}}$ The slope is slightly higher for the nanocomposite layer, suggesting faster diffusion of ions into the porous structure. The knee frequency is equal to $1 \mathrm{kHz}$ for pEDOT/PSS and $1.45 \mathrm{kHz}$ for the (p)N-CNTs/pEDOT/PSS electrode. The higher knee frequency for the nanocomposite indicates that a stable electric double-layer is formed over a wider range of frequencies. This is evidence that the (p)N-CNTs/pEDOT/PSS electrode may be more rapidly charged and discharged than the pEDOT/PSS electrode. In the low frequency region the slope of the Nyquist curve is nearly parallel to the imaginary axis. Such behaviour is typical for ideal capacitors with fast kinetics of charge flow processes.

The dependence between the specific capacitance and frequency (Fig. 12) exhibits an almost horizontal slope in the low frequency region. The specific capacitance values $(C)$ were calculated from the imaginary part of the impedance spectra $\left(-Z^{\prime \prime}\right)$ according to eqn $(1):^{84,85}$

$$
C=-\frac{1}{2 \pi f m_{\mathrm{e}} Z^{\prime \prime}}
$$

where $f$ - frequency $(\mathrm{Hz}), m_{\mathrm{e}}$ - the mass of active material of one electrode. These values are in agreement with the capacitance values obtained from cyclic voltammetry and chronopotentiometry measurements. Based on the EIS measurement, one can conclude that the presence of plasma treated carbon nanotubes in the polymer matrix changes the resistance of the electrode layer, improves the diffusion processes and increases the capacitance values.

\section{Conclusions}

A facile method of flowing plasma treatment was applied for efficient modification of carbon nanotubes. The presented method allows to process the samples in the form of powder without using any solvent. Moreover, it is easy to control the synthesis conditions and influence the properties of the final product. Carbon nanotubes modified in optimised plasma conditions contain approx. $3.8 \%$ of nitrogen, mostly in pyridinic form. Modified (p)N-CNTs, due to the presence of nitrogen functional groups, exhibit better dispersibility in water, higher capacitance values compared to pristine CNTs. A novel nanocomposite (p)N-CNTs/pEDOT/PSS was synthesized and tested for supercapacitor application. The nanocomposite electrode layers exhibit two times higher capacitance values (above $100 \mathrm{~F} \mathrm{~g}^{-1}$ ), improved stability (95\% capacitance retention after 1000 cycle in neutral electrolyte), lower resistance and easier diffusion than pure polymer layers. These features suggest that the (p)N-CNTs/pEDOT/PSS nanocomposite is a suitable electrode material for high-power application.

\section{Acknowledgements}

The financial support from Norway Grants in the PolishNorwegian Research Programme (Small Grant Scheme) operated by the National Centre for Research and Development, grant no. POL-NOR/209673/9/2013 is gratefully acknowledged. The authors thank Jacek Ryl for XPS measurements.

\section{References}

1 L. Dai, D. W. Chang, J.-B. Baek and W. Lu, Small, 2012, 8, 1130-1166.

2 M. Garzia Trulli, E. Sardella, F. Palumbo, G. Palazzo, L. C. Giannossa, A. Mangone, R. Comparelli, S. Musso and P. Favia, J. Colloid Interface Sci., 2017, 491, 255-264.

3 L. Dai, Y. Xue, L. Qu, H.-J. Choi and J.-B. Baek, Chem. Rev., 2015, 115, 4823-4892.

4 W.-M. Chang, C.-C. Wang and C.-Y. Chen, Electrochim. Acta, 2015, 186, 530-541.

5 S. Van Dommele, Nitrogen Doped Carbon Nanotubes: synthesis, characterization and catalysis, University of Utrecht, 2008.

6 W. J. Lee, U. N. Maiti, J. M. Lee, J. Lim, T. H. Han and S. O. Kim, Chem. Commun., 2014, 50, 6818-6830.

7 D. Higgins, Nitrogen-Doped Carbon Nanotubes and their Composites as Oxygen Reduction Reaction Electrocatalysts for Low Temperature Fuel Cells, Master's thesis, University of Waterloo, 2011.

8 S. Hussain, R. Amade, E. Jover and E. Bertran, J. Mater. Sci., 2013, 48, 7620-7628.

9 M. Y. Ghotbi and M. Azadfalah, Mater. Des., 2016, 89, 708714.

10 H. Liu, H. Song, X. Chen, S. Zhang, J. Zhou and Z. Ma, J. Power Sources, 2015, 285, 303-309.

11 M. Antonietti and K. Müllen, Chemical Synthesis and Applications of Graphene and Carbon Materials, Wiley-VCH Verlag GmbH, Weinheim, 2017.

12 Y. H. Lee, K. H. Chang and C. C. Hu, J. Power Sources, 2013, 227, 300-308. 
13 G. Lota, K. Lota and E. Frackowiak, Electrochem. Commun., 2007, 9, 1828-1832.

14 F. Béguin, V. Presser, A. Balducci and E. Frackowiak, Adv. Mater., 2014, 26, 2219-2251.

15 J. McMurry, Organic Chemistry, Thomson, 7th edn, 2008.

16 C. P. Ewels, M. Glerup and V. Krstic, Nitrogen and boron doping in carbon nanotubes chapter in Chemistry of Carbon Nanotubes, ed. V. A. Basiuk and E. V. Basiuk, American Scientific Publishers, 2008.

17 Q. Wei, X. Tong, G. Zhang, J. Qiao, Q. Gong and S. Sun, Catalysts, 2015, 5, 1574-1602.

18 N. G. Tsierkezos, S. H. Othman, U. Ritter, L. Hafermann, A. Knauer, J. M. Köhler, C. Downing and E. K. McCarthy, Sens. Actuators, B, 2016, 231, 218-229.

19 N. Alexeyeva, E. Shulga, V. Kisand, I. Kink and K. Tammeveski, J. Electroanal. Chem., 2010, 648, 169-175.

20 Z. Chen, D. Higgins and Z. Chen, Carbon, 2010, 48, 30573065.

21 D. Higgins, Z. Chen and Z. Chen, Electrochim. Acta, 2011, 56, 1570-1575.

22 M. I. Ionescu, Y. Zhang, R. Li, H. Abou-Rachid and X. Sun, Appl. Surf. Sci., 2012, 258, 4563-4568.

23 A. R. John and P. Arumugam, J. Power Sources, 2015, 277, 387-392.

24 G. Keru, P. G. Ndungu and V. O. Nyamori, J. Nanomater., 2013, 2013, 7.

25 A. A. Koós, F. Dillon, E. A. Obraztsova, A. Crossley and N. Grobert, Carbon, 2010, 48, 3033-3041.

26 A. Z. Sadek, V. Bansal, D. G. McCulloch, P. G. Spizzirri, K. Latham, D. W. M. Lau, Z. Hu and K. Kalantar-Zadeh, Sens. Actuators, B, 2011, 160, 1034-1042.

27 V. Thirumal, A. Pandurangan, R. Jayavel, S. R. Krishnamoorthi and R. Ilangovan, Curr. Appl. Phys., 2016, 16, 816-825.

28 R. Kumar, R. K. Singh and R. S. Tiwari, Mater. Des., 2016, 94, 166-175.

29 J.-B. Kim, S.-J. Kong, S.-Y. Lee, J.-H. Kim, H.-R. Lee, C.-D. Kim and B.-K. Min, J. Korean Phys. Soc., 2012, 60, 1124-1128.

30 A. Kumar, S. Parveen, S. Husain, J. Ali, M. Zulfequar, Harsh and M. Husain, Appl. Surf. Sci., 2014, 322, 236-241.

31 A. U. Haq, J. Lim, J. M. Yun, W. J. Lee, T. H. Han and S. O. Kim, Small, 2013, 9, 3829-3833.

32 A. Salar Elahi, K. Mikaili Agah and M. Ghoranneviss, Results Phys., 2017, 7, 757-761.

33 C. Kim, H.-R. Lee and H. T. Kim, Mater. Chem. Phys., 2016, 183, 8-12.

34 B. Fragneaud, K. Masenelli-Varlot, A. González-Montiel, M. Terrones and J. Y. Cavaillé, Chem. Phys. Lett., 2007, 444, 1-8.

35 F. Villalpando-Paez, A. Zamudio, A. L. Elias, H. Son, E. B. Barros, S. G. Chou, Y. A. Kim, H. Muramatsu, T. Hayashi, J. Kong, H. Terrones, G. Dresselhaus, M. Endo, M. Terrones and M. S. Dresselhaus, Chem. Phys. Lett., 2006, 424, 345-352.

36 J. J. Adjizian, R. Leghrib, A. A. Koos, I. Suarez-Martinez, A. Crossley, P. Wagner, N. Grobert, E. Llobet and C. P. Ewels, Carbon, 2014, 66, 662-673.
37 L. Shi, M. Sauer, O. Domanov, P. Rohringer, P. Ayala and T. Pichler, Phys. Status Solidi B, 2015, 252, 2558-2563.

38 C. H. Choi, S. Y. Lee, S. H. Park and S. I. Woo, Appl. Catal., B, 2011, 103, 362-368.

39 C. H. Choi, S. H. Park and S. I. Woo, Appl. Catal., B, 2012, 119-120, 123-131.

40 D. P. Dubal, N. R. Chodankar, Z. Caban-Huertas, F. Wolfart, M. Vidotti, R. Holze, C. D. Lokhande and P. Gomez-Romero, J. Power Sources, 2016, 308, 158-165.

41 K. Kordatos, A. D. Vlasopoulos, S. Strikos, A. Ntziouni, S. Gavela, S. Trasobares and V. Kasselouri-Rigopoulou, Electrochim. Acta, 2009, 54, 2466-2472.

42 X. Li, L. Kong, J. Yang, M. Gao, T. Hu, X. Wu and M. Li, Appl. Phys. A: Mater. Sci. Process., 2013, 113, 735-739.

43 Z. Xu, H. Li, M. Fu, H. Luo, H. Sun, L. Zhang, K. Li, B. Wei, J. Lu and X. Zhao, J. Mater. Chem., 2012, 22, 18230.

44 Z. Zhao, Y. Dai, G. Ge, X. Guo and G. Wang, Phys. Chem. Chem. Phys., 2015, 17, 18895-18899.

45 Y. Wang, Y. Liu, W. Liu, H. Chen, G. Zhang and J. Wang, Mater. Lett., 2015, 154, 64-67.

46 T. Pan, H. Liu, G. Ren, Y. Li, X. Lu and Y. Zhu, Science Bulletin, 2016, 61, 889-896.

47 A. Ben Belgacem, I. Hinkov, S. Ben Yahia, O. Brinza and S. Farhat, Mater. Today Commun., 2016, 8, 183-195.

48 M. Glerup, J. Steinmetz, D. Samaille, O. Stéphan, S. Enouz, A. Loiseau, S. Roth and P. Bernier, Chem. Phys. Lett., 2004, 387, 193-197.

49 R. I. Zhao, Y. Ma, J. Zhang, F. Li, W. Liu and Q. Cui, Mater. Sci., 2010, 28, 189-198.

50 J. Cao, T. Huang, R. Liu, X. Xi and D. Wu, Electrochim. Acta, 2017, 230, 265-270.

51 H. T. Ham, C. M. Koo, S. O. Kim, Y. S. Choi and I. J. Chung, Macromol. Res., 2004, 12, 384-390.

52 Z. Zhao, Z. Yang, Y. Hu, J. Li and X. Fan, Appl. Surf. Sci., 2013, 276, 476-481.

53 A. Yıldrım and T. Seçkin, Adv. Mater. Sci. Eng., 2014, 2014, 16.

54 P. Santhosh, A. Gopalan and K. P. Lee, J. Catal., 2006, 238, 177-185.

55 B. Pan, D. Cui, R. He, F. Gao and Y. Zhang, Chem. Phys. Lett., 2006, 417, 419-424.

56 M. Sevilla, L. Yu, L. Zhao, C. O. Ania and M. Titiricic, ACS Sustainable Chem. Eng., 2014, 2, 1049-1055.

57 Y. Li and N. Chopra, Carbon, 2014, 77, 675-687.

58 M. Garzia Trulli, E. Sardella, F. Palumbo, G. Palazzo, L. C. Giannossa, A. Mangone, R. Comparelli, S. Musso and P. Favia, J. Colloid Interface Sci., 2017, 491, 255-264.

59 Z. Chen, X. J. Dai, P. R. Lamb, D. R. De Celis Leal, B. L. Fox, Y. Chen, J. Du Plessis, M. Field and X. Wang, Plasma Processes Polym., 2012, 9, 733-741.

60 L. G. Nair, A. S. Mahapatra, N. Gomathi, K. Joseph, S. Neogi and C. P. R. Nair, Appl. Surf. Sci., 2015, 340, 64-71.

61 R. Chetty, S. Kundu, W. Xia, M. Bron, W. Schuhmann, V. Chirila, W. Brandl, T. Reinecke and M. Muhler, Electrochim. Acta, 2009, 54, 4208-4215.

62 A. Gohel, K. C. Chin, Y. W. Zhu, C. H. Sow and A. T. S. Wee, Carbon, 2005, 43, 2530-2535. 
63 Y. H. Lai, H. Bin Lian and K. Y. Lee, Diamond Relat. Mater., 2009, 18, 544-547.

64 G. R. S. Iyer and P. D. Maguire, J. Mater. Chem., 2011, 21, 16162.

65 A. Dettlaff and M. Wilamowska, Synth. Met., 2016, 212, 3143.

66 R. Bogdanowicz, M. Sawczak, P. Niedzialkowski, P. Zieba, B. Finke, J. Ryl, J. Karczewski and T. Ossowski, J. Phys. Chem. C, 2014, 118, 8014-8025.

67 B.-J. Kim, J.-P. Kim and J.-S. Park, Nanoscale Res. Lett., 2014, 9, 236.

68 P. Niedziałkowski, T. Ossowski, P. Zięba, A. Cirocka, P. Rochowski, S. J. Pogorzelski, J. Ryl, M. Sobaszek and R. Bogdanowicz, J. Electroanal. Chem., 2015, 756, 84-93.

69 K. Siuzdak, M. Ficek, M. Sobaszek, J. Ryl, M. Gnyba, P. Niedziałkowski, N. Malinowska, J. Karczewski and R. Bogdanowicz, ACS Appl. Mater. Interfaces, 2017, 9(15), 12982-12992.

70 R. Arrigo, M. Hävecker, R. Schlögl and D. S. Su, Chem. Commun., 2008, 4891-4893.

71 V. Datsyuk, M. Kalyva, K. Papagelis, J. Parthenios, D. Tasis, A. Siokou, I. Kallitsis and C. Galiotis, Carbon, 2008, 46, 833-840.

72 O. Beyssac, B. Goffe, J. Petitet, E. Froigneux and M. Moreau, Spectrochim. Acta, Part A, 2003, 59, 2267-2276.
73 T. Sharifi, F. Nitze, H. R. Barzegar, C. W. Tai, M. Mazurkiewicz, A. Malolepszy, L. Stobinski and T. Wagberg, Carbon, 2012, 50, 3535-3541.

74 S. Y. Wang, X. S. Zhao, T. Cochell and A. Manthiram, J. Phys. Chem. Lett., 2012, 3, 2164-2167.

75 Y. Xiao, X. Cui and D. C. Martin, J. Electroanal. Chem., 2004, 573, 43-48.

76 Y. Ma, F. Zhao and B. Zeng, Talanta, 2013, 104, 27-31.

77 M. Wilamowska and A. Lisowska-Oleksiak, Solid State Ionics, 2011, 188, 118-123.

78 V. Khomenko, E. Raymundo-Piñero and F. Béguin, J. Power Sources, 2010, 195, 4234-4241.

79 M. Seredych, M. Koscinski, M. Sliwinska-Bartkowiak and T. J. Bandosz, J. Power Sources, 2012, 220, 243-252.

80 Z. Mousavi, J. Bobacka, A. Lewenstam and A. Ivaska, J. Electroanal. Chem., 2009, 633, 246-252.

81 W. J. Albery and A. R. Mount, J. Chem. Soc., Faraday Trans., 1993, 89, 2487.

82 P. G. Pickup, J. Chem. Soc., Faraday Trans., 1990, 86(21), 3631-3636.

83 X. Ren and P. G. Pickup, J. Chem. Soc., Faraday Trans., 1993, 89, 321.

84 M. Skunik-Nuckowska, P. Bacal and P. J. Kulesza, J. Solid State Electrochem., 2015, 19, 2753-2762.

85 Y.-G. Wang, Z.-D. Wang and Y.-Y. Xia, Electrochim. Acta, 2005, 50, 5641-5646. 